\title{
Tactics of Promoting Cultural of Urban Landscape in Gansu Province
}

\author{
Qian Yuanyuan ${ }^{1}$, Song Zehai ${ }^{2}$ \\ ${ }^{1}$ School of Art and Design, Lanzhou Jiaotong University, Lanzhou, 730070, China \\ ${ }^{2}$ Gansu Province Transportation Planning, Survey and Design Institute Co., Ltd., Lanzhou, 730030, China
}

Keywords: City, Landscape, Dunhuang Arts

\begin{abstract}
This paper takes green landscape cultural ecological city theory and green living environment theory as the guide, improving the ecological quality as the goal, sustainability as the development strategy. The paper makes an analysis of building green landscape and cultural ecological protection system from three aspects, studies cultural of waterfront landscape in Gansu and artistic elements of Dunhuang. The aim of this research is to build clear, well-structured urban landscape of Gansu, effectively enhancing cultural of urban landscape of Gansu and finally creating a good environment for the social and economic development in Gansu Province.
\end{abstract}

\section{Role of Gansu Province City's Cultural Soft Power Construction}

Gansu climatic conditions and limited water resources make the developments of the quality of the urban environment and urban transition tourism city be uncoordinated ${ }^{[1]}$. Environmental problems have become more obvious, population growth, traffic congestion, air pollution, and so on ecological environmental problems manifested in varying degrees, seriously affecting the sustainable development of the city of Gansu. Currently, the lack of Gansu province city, the original variety of zoning organic coordination among themselves, cannot meet the ecological landscape construction process integrated development of land and water resources, efficient use and protection needs. Urban landscape and cultural soft power has become an important factor to measure the status of urban civilization and the modern city, how to use the limited urban land resources to achieve rational distribution of urban green landscape and cultural systems, to optimize the soft power of landscape spatial structure, reflecting the local culture is the city's soft power system fully and efficiently play its ecological and social benefits, it is very important. For building a tourist city, Gansu province city shall use hard power as base and soft power as attractive and appealing of the city. Urban culture and its building of soft power is an important aspect that should be indispensable. In recent years, Gansu province city' tourism relying on the rich resources of cultural landscape gained rapid development. However, in terms of life-cycle theory of Gansu province city tourism image is still in the development stage, the first image perception is not clear; secondly is the tourism market has a low degree of recognition on the image and lack uniqueness. Therefore, Gansu urban landscape and cultural soft power research has important theoretical and practical significance. This article from Gansu province city landscape and cultural soft power to enhance the strategic point of view, discuss preliminary observations.

\section{The Problem of Enhancing the Soft Power of Gansu Province City}

Cityscape cultural soft power is the value of urban living systems and their symbolic form of specific human community to the outside presents flexible attraction and appeal [3]. Beauty of a Gansu province city contains a "weather, geography, history, customs, architecture, art" and "all beauty is ready" and "a collection of beauty." Mention of Gansu, people always think of beef noodles, carved gourds, clay art, sheepskin raft, paper cutting arts and so on. I assume the study process of the young science research projects in Gansu Jiaotong University, "Enhancement of Gansu province disaster mitigation capacity building of cities green culture protection system", basing on the relevant theory collect a variety of data, obtained in cooperation with relevant departments to collect profiles of Gansu province city area, including collection of natural 
conditions, socio-economic conditions and cultural science and technology information. Do related researches Basing on logical analysis, by comparison with the analogy, abstraction and generalization method, analysis and synthesis method, inductive and deductive logic, such as specific methods to explore the interior of the regularity of the urban landscape and cultural soft Gansu in-depth study of the strength of the system.

Through on-site and site visits to gather information, the paper will determine public satisfaction survey focused on studies of Gansu province city waterfront landscape and cultural. Summarize Experience of the problems and achievements and success for the production of a detailed questionnaire conducted a comprehensive analysis of the data, the urban landscape of Gansu province city's cultural soft power system for research and demonstration. Follows.

\subsection{Green Network System is Not Perfect}

Gansu Yellow River along the transport routes and forest green corridor landscape, patchy shelter, and not to scale systems, urban green spaces did not meet the ecological protection because of not forming network, poor connectivity and low road green coverage rate. Due to the low road green coverage rate of the city, difficult to form a green corridor and connect the city flake of green area, Ecological benefits of urban green space cannot play very well. Both sides of the river runs through the city, building densely, near the river, lack of covering vegetation, coupled with the river within the city limits and many more rigid construction materials lining, self-purification capacity of water bodies weak, waterfront natural ecological environment has been completely destroyed, the basic loss the river the role of biological corridor. Due to the lag of network construction of city green space, the city residents rarely use green space, and social benefit is low.

\subsection{Urban Landscape Regional Characteristics are Not Distinctive Enough}

Urban landscape culture from the traditional damage results in reduced recognition and the lack of culture characteristics of urban landscape, hinders the sustainable development of the city. Urban landscape is often associated with the famous buildings, such as Beijing's Tiananmen square, the Imperial Palace and the Wangfujing street, Shanghai's Bund, the "Oriental Pearl" TV Tower and the Nanjing Road, Xi'an's big wild goose pagoda and the Mausoleum of the First Qin Emperor, which have become signs and symbols of the city [4]. Gansu is the only one in the Yellow River through the city. Based on skeleton of "two mountains and a river", only Zhongshan bridge is famous for its strong local characteristics and profound history. However, the whole city is still a lack of landmark region of high grade culture, distinctive local characteristics.

\subsection{The Shaping of Urban Landscape Lack Ecological Consciousness and Humanistic Care}

Gansu is relatively sensitive ecological area in ecological function zoning of Gansu province. Taking biodiversity and habitat as the main sensitive factors, it faces that problem that plant species is single and community structure is monotonous, unreasonable phenomenon in the construction of green landscape of cultural soft power, which is not conducive to the improvement of the ecological environment and sustainable development. Currently, urban Construction has too much emphasis on display and visual form to beautify the urban environment. Urban ecological environment quality also affects the degree of interference between the city, so it has a high demand on the protection forest system. At present, in Gansu the rate of forest coverage is low, mainly displays in: "Forest patches" and "Lin Lang" have no size; protection forest is not perfect. With the development of the city, the highway traffic had a serious impact on the ecological environment, atmospheric environment, acoustic environment, natural landscape. Most protection system on both sides do not become dimensions. On both sides of the railway forest is sparse, landscape is poor and protection ability is weak.

\section{Countermeasures of Improving Soft Power in Gansu}

\subsection{Ecological Protection System Construction of Green Culture Landscape in Gansu}

Ecological landscape emphasizes the mutual relationship between the level of process and 
landscape pattern, and the project view" patch - corridor - matrix" as a basic mode of landscape analysis. For ecological landscape measure and strengthening ecological landscape heterogeneity and continuity in Gansu. Embodied in: enclosure and recovery of vegetation patches, artificial recovery of patch, the patch of extended recovery, reconstruction of famous ornamental forest patches and seedlings exhibit plaque, and repairing the ecological corridor. Based on the analysis we get concrete planning and design of ecological landscape pattern, and the formation of the patch and corridor: Fencing plaques, plaques pasture, woodland patches, building square plaque, plaque water, trees corridors, river corridors and road corridor. All kinds of patches and corridors cross each other to form networks, and make it with the function of vegetation restoration plots and pasture restoration plots habitat matrix that is more extensive and close. In urban and suburban green space, through ecological protection system, combined with the implementation of key projects, it gradually formes the perfect ecological function, beautiful environment and comfortable living environment. Planning of the city and rural elements blend in space, making the city and countryside realize complementary in function, and we can create a natural and idyllic ideal home to make full use of and enjoy the modern city life. In the center of the city, through the integration of connection point and the natural elements (such as parks, squares), that includes the artificial environment, open space (such as parks, squares), Bridge Street and so on. In the maintenance of biological diversity, the premise to reduce air pollution, we can provide comfortable living space and urban Transport for the residents.

The construction of Ecological Garden City, it not only helps the city improve visibility, but also helps to improve the city's operating efficiency and economic vitality, helps to strengthen the city agglomeration and radiation ability and eliminates the sharp conflict between the environment and the development for a long time that we build a people-oriented society to coordinate and balance the three factors that includes economic, social, natural environment. At last, the city maintains its vigor and vitality and improves the comprehensive competitiveness of Gansu in attracting talents, technology, funds and so on.

\subsection{Enhance the Cultural Soft Power of Waterfront Landscape in Gansu}

The city (Scenic Area) tend to architecture art and landscape to emphasize the harmony and native environment and local culture of artistic conception. This paper focuses on the region, the Yellow River customs line located in Gansu province city. This area has great biological diversity, Wet Island as city oasis for survival, has important significance of landscape ecology. The area is the focus of ecological control area, mainly to protect, restore and control, strictly controlling on water quality protection. Ecological control area, mainly to protect, restore and control, strictly controlling on water quality protection.

At present, the main problems of ecological environment in this area are: ecological environment damaged, water pollution, soil erosion situation in the upper reaches of the the Yellow River. So, must set up to Construction of ecological protection zone of the upper reaches of the Yellow River as the center as soon as possible. The district is the important support and strong backing of city capacity and landscape security. We should strictly control the construction project, to maintain the landscape ecological process of nature and semi nature complete and continuous.

Lan River is key protection recovery corridor. Strive to improve the water self purification ability by restoring the natural ecological environment in the main region. Both sides of Downstream main river in "The Yellow River" build natural ecological coastline that forms width 50 meters in the ecological system composed of vegetation. It can be narrowed in the urban part. Both sides of protection zone of the upstream water sources control natural ecological protection zone of 3000 meters.1000 meters for the strict protection control zone, 2000 meters for the relative protection control zone and new forest. City ecology protection system is important to adjust and set the corridor or plaque in landscape ecological scale. In this way, we can solve a series of ecological and economic problems brought by the line flow in urban ecological material and energy system. Considering integrity and connectivity in regional landscape system, based on reasonable planning, we eventually establish stable ecology protection system. 


\subsection{Dunhuang Culture and Art Elements in the Urban Landscape in Gansu}

\subsubsection{Study of Dunhuang Mogao Grottoes Buddhist Culture}

There is a link between Dunhuang Buddhist culture and regional space, deep history origin in Gansu area. Dunhuang is the ancient Communicational throat and is the intersection of Chinese and Western culture. From Zhang Sai to the western regions, the leader, Huo Qubing, expelled out the Huns in Hexi area. We stationed the migration to open up wasteland and set off to build the county. Thence the Central Plains and the western countries and many ethnic frequently exchanged, and gradually established the position of the western city of Dunhuang. At this time, the India Buddhist accompanied by the deepening of Chinese and Western exchanges, gradually spread to Dunhuang and the Central Plains. Then the grotto is as the Buddhist activities, which developed with the Buddhism grottoes, Mogao Grottoes appeared in this context the emergence. In the Sui and Tang Dynasty, The Buddhist story painting mostly selected one or two representative plot to show, and the caves often in frontal niches on both sides, were painted two plots, "the ride as the mole" and "midnight more than city", with decorative effect. A typical example Mogao Grottoes is fifty-seventh cave, cave 209th and 329th cave. Stories of Buddhism is one of the important content of Buddhist murals, in each period and each area, temples and Grottoes have different performance, which reflect the characteristics of Buddhist art in different regions. This paper derives the essence of Buddhist culture in Dunhuang art, to explore how to use temple culture in Gansu landscape, to enrich temple garden elements in Gansu, and to build the unique cultural landscape in Gansu province.

\subsubsection{Historical Research of Silk Road and Dunhuang Art}

The rise and fall of Dunhuang culture, prosperity and decline are closely linked with the Silk Road. Since the Han Dynasty, the Silk Road for the long-term prosperity, providing a great space for communication and exchange of Chinese and Western culture, Dunhuang located in the silk road routes in cultural exchange and fusion of East1 and West, develop its own unique culture and art. Why is the ancient Dunhuang culture to prosper, it is because of the rich nutrition from western culture along the Silk Road. This paper study on the road of art and silk culture of Dunhuang from landscape and cultural history of the development of Gansu.

\subsubsection{Research on the Relationship between Urban Landscape Features and Dunhuang Frescoes, Painted Sculpture Art Elements}

The grottoes of Dunhuang as a world cultural heritage of mankind has made many achievements in the protection of research, and provides an important resource for modern art academic research, innovation, tourism and other aspects, based on the Dunhuang murals and painted sculpture art. This paper studying the distribution of Dunhuang mural refers to the vast area including Party River Basin and Shule River Basin of the grotto temple murals, and the Mogao Grottoes in Dunhuang is the most representative. Any art is rooted in real life, any art has its national tradition, therefore they form for common art language and skill and have the same ethnic style. We can use the Dunhuang murals elements in construction, landscaping, sculpture, landscape art, landscape, cultural landscape in Gansu.

Dunhuang sculpture craft as the intangible cultural heritage is a kind of art and its subject are mainly many characters of Buddhism, occupying an important position in the caves around, with colorful murals as embellishment. This color clay production, because of the material, process and a certain way , has one's own knack, so it has very strong plasticity and distinctive works has the advantages of firmness, durability, resistance to weathering. The paper applys excavation and finishing of the Dunhuang sculpture craft, in-depth study of Dunhuang grotto color clay production process and material selection, formula, technique to the sculpture and art market in Gansu.

\subsubsection{Research on Dunhuang Art Elements in the Development of Cultural Tourism Resources in Gansu}

Combining Gansu province city landscape culture with Dunhuang art elements is in favor of 
development of tourism resource development and cultural industry, so as to enhance the Gansu province city cultural landscape construction. Through the research discovery, in Gansu the tourism resources focuses on the Silk Road and the grotto art, urban landscape perception is the largest in Dunhuang and Gansu, in tourist landmark landscape perception Dunhuang flying is the most. Obviously, the point of tourism landscape perception in Gansu is focused on the cultural characteristics of Dunhuang landscape. Therefore, tourism landscape image in Gansu should be based on the perceived image in Dunhuang art elements and strengthens the comprehensive perception of image culture landscape features. This dissertation focuses on the research of the subject of the Dunhuang technology products, cultural products, tourism products research, development, production, sales, exhibitions and so on.

\section{Conclusions}

Cultural is the important composition and the basis ${ }^{[5]}$ of urban. Culture in the urban landscape to improve the city's ecological, environmental quality, disaster prevention and avoidance, amenity, plays a leading role in regulating the ecological balance of the city. Landscape cultural to reflect the city's historical context and the cultural connotation, form and color symbols reflect the city culture temperament and image, and reflect the city spirit and philosophy, which shapes urban cultural image ${ }^{[1]}$.Landscape cultural power in Gansu includes three aspects that are the construction of green landscape, cultural and ecological protection system in Gansu ,cultural power research of waterfront landscape and the application of Dunhuang art. Taking a variety of ecological protection and construction measures suit one's measures to local conditions, use of colorful plant species and planting form make up for the shortage of city biodiversity, and form a rich variation, a prominent feature of the urban landscape. Improvement of urban green space layout structure and network system, forms the main urban areas of the ecological protection and green landscape corridor. In the process of ecological urban construction, regional municipal facilities will be further improved, building and landscape will coordinate with each other, urban characteristics and image will gradually emerge, thus improving the position of Gansu in the capital city of northwest region and in the nation wider area within the scope of the role, to improve the living environment and promote the residents material civilization and life quality. We should strengthen the city vigor and improve the city's comprehensive competitiveness.

\section{References}

[1] Joseph S. Nye, Jr. Soft Power [J]. Foreign Policy, 1990 (80):153 -171.

[2] Wu Biao, Landscape symbols optimization design of city cultural image [J]. Literature and Art Studies, 2012 (09): P148.

[3] Wang Yichuan, Beijing cultural symbols and world city soft power construction [J]. Social Science of Beijing, 2011 (02): P4-5.

[4] Wang Xi, city tourism landscape on moulding [J]. Journal of Guilin Institute of Tourism, 2003(03): P64.

[5] Zhang Hui, Wang Yan, Based on the construction of cultural soft power of city development [J]. Future and Development. 2012(08): P66. 